\title{
Legislación de emergencia y reforma laboral en España (2011-2012)
}

\section{Emergency legislation and labor reform in Spain (2011-2012)}

\author{
ANTONIO V. SEMPERE*
}

Resumen: El Derecho del Trabajo español está atravesando una etapa de continuas y desordenadas reformas, la mayoría de ellas realizadas a través de normas aprobadas por el Gobierno invocando razones de urgencia. Aquí se da cuenta de seis reales decretos leyes recientes y relevantes aprobados entre 2010 y 2012.

Palabras clave: reforma laboral - legislación laboral de emergencia

Summary: Spanish Labor Law is going through a phase of continuous and disordered reforms, most of them made through approved rules by the Government invoking raisons of urgency. Here are explained six recent and relevant Royal Decrees-Laws approved between 2010 and 2012.

Keywords: labor reform - emergency labor legislation

CONTENIDO: I. INTRODUCCIÓN.- II. REAL DECRETO LEY 10/2010, DE 16 DE JUNIO, SOBRE MEDIDAS URGENTES PARA LA REFORMA DEL MERCADO DE TRABAJO.- III. REAL DECRETO LEY 1/2011, DE 11 DE FEBRERO, DE EMPLEO ESTABLE Y RECUALIFICACIÓN PROFESIONAL.- IV. REAL DECRETO-LEY 5/2011, DE 29 DE ABRIL, SOBRE EMPLEO SUMERGIDO.- IV.1. CUESTIONES GENERALES.- IV.2. INCUMPLIMIENTOS REGULARIZABLES.- IV.3. EFECTOS DE LA REGULARIZACIÓN.-IV.4. SANCIONES ESPECÍFICAS.-V. REAL DECRETO LEY 7/2011,DE10DEJUNIO, SOBRENEGOCIACIÓNCOLECTIVA.-V.1.UNAREFORMA «IMPUESTA».- V.2. UNA REFORMA «PROVISIONAL».- V.3. UN ENVOLTORIO NORMATIVO CUESTIONABLE.- V.4. UNOS PRESUPUESTOS HABILITANTES DUDOSOS.- V.5. UNA FIGURA DISCUTIBLE.- V.6. NÚCLEOS BÁSICOS.V.7. OBJETIVOS.- V.8. OTRAS CUESTIONES.- VI. REAL DECRETO LEY 10/2011, DE 26 DE AGOSTO, SOBRE EMPLEO Y DESEMPLEO.- VI.1. CONTRATO PARA LA FORMACIÓN Y EL APRENDIZAJE.- VI.2. OTRAS CUESTIONES.- VII. REAL DECRETO LEY 3/2012, DE MEDIDAS URGENTES PARA LA REFORMA DEL MERCADO LABORAL.- VII.1. CONTENIDO DE LA REFORMA.- VII.2. OPINIÓN TÉCNICA

* Catedrático de la Universidad Rey Juan Carlos (Madrid), socio del Estudio Gómez-Acebo \& Pombo, director de Aranzadi Social $y$ Profesor Honorario de la UDEP. 


\section{INTRODUCCIÓN}

Al hilo de la persistente y grave crisis económica por la que atraviesa nuestro país, el ordenamiento laboral viene siendo sometido a un continuo proceso de cambios, la mayoría inspirados por la ilusión de atajar o aminorar los perniciosos efectos de aquella. En particular, durante los tres últimos años se ha observado una utilización desmesurada de la legislación de emergencia. El Gobierno, amparado en la hipótesis constitucional de la extraordinaria y urgente necesidad, aprueba una norma con rango de ley («real decreto ley»), luego sometida a convalidación del Parlamento. Realizaremos aquí un inventario de las materias abordadas por los más relevantes:

- El Real Decreto Ley 10/2010, de 16 de junio, sobre Reforma del Mercado de Trabajo.

- El Real Decreto Ley 1/2011, de 11 de febrero, de Empleo Estable y Recualificación Profesional.

- El Real Decreto Ley 5/2011, de 29 de abril, sobre Empleo Sumergido.

- El Real Decreto Ley 7/2011, de 10 de junio, sobre Negociación Colectiva.

- El Real Decreto Ley 10/2011, de 26 de agosto, sobre Empleo y Desempleo.

- El Real Decreto Ley 3/2012, de 10 de febrero, de Medidas Urgentes para la Reforma del Mercado Laboral.

¿Cómo puede explicarse que, de repente, todos los problemas laborales acaben siendo urgentes, que los Gobiernos de uno u otro signo sucumban a esa tentación? Mejor pasemos a ejemplificar lo dicho con el examen de lo realizado por la última de las normas citadas: sus razones de fondo (que quieren corresponderse con los presupuestos constitucionales de «extraordinaria y urgente necesidad») son las que aparecen encabezando la densa Exposición de Motivos de la norma:

- La destrucción de empleo que viene dándose en los últimos años ${ }^{1}$, con especial incidencia en la población juvenil².

1 La crisis económica que atraviesa España desde 2008 ha puesto de relieve las debilidades del modelo laboral español. La gravedad de la crisis actual no tiene precedentes. España ha destruido más empleo, y más rápidamente, que las principales economías europeas. Los datos de la última Encuesta de Población Activa describen bien esta situación: la cifra de paro se sitúa en 5273600 personas, con un incremento de 295300 en el cuarto trimestre de 2011 y de 577000 respecto al cuarto trimestre de 2010. La tasa de paro sube en 1,33 puntos respecto al tercer trimestre y se sitúa en el $22,85 \%$.

2 La destrucción de empleo ha sido más intensa en ciertos colectivos, especialmente los jóvenes cuya tasa de paro entre los menores de 25 años alcanza casi el 50\%. La incertidumbre a la hora de entrar en el mercado de trabajo, los reducidos sueldos iniciales y la situación económica general 
- La prolongada duración del desempleo, es decir, la dificultad de acceso a un nuevo empleo por parte de quienes lo han perdido 3 .

- La dualidad de la población activa, segregada peligrosamente entre estable y una elevada cifra de empleados temporales ${ }^{4}$.

- Los perniciosos efectos que sobre la Seguridad Social posee esa negativa evolución del empleo y la consiguiente prologada atención a quienes lo han perdido5.

Ante esa negativa situación económica y del empleo, el Ejecutivo entendió que era preciso adoptar una reforma inmediata, mucho más cercana actuando por esta vía de urgencia que recurriendo a la legislativa; pese a la mayoría absoluta con que cuenta en las Cámaras el Partido Popular. Sin embargo, desde el principio contrarrestó esa relativa unilateralidad en la aprobación del texto reformista con el anuncio de su tramitación como proyecto de ley. De ese modo, no es la voluntad del Gobierno (se viene a decir), sino la muy deficiente situación del mercado laboral español la causa de que se haya de recurrir a este método normativo ${ }^{6}$.

Pese a la relativa neutralidad con que se desea justificar la técnica seguida (hay un problema muy grave, debe resolverse de inmediato), en esa decisión tampoco resulta complicado encontrar una censura al régimen jurídico preexistente, necesitado de rápida y profunda revisión:

- Se quiere proporcionar a los operadores económicos y laborales un horizonte de seguridad jurídica y confianza en el que desenvolverse con certeza para conseguir recuperar el empleo.

- La norma pretende crear las condiciones necesarias para que la economía española pueda volver a crear empleo y así generar la seguridad necesaria para trabajadores y empresarios, para mercados e inversores.

están provocando que muchos jóvenes bien formados abandonen el mercado de trabajo español y busquen oportunidades en el extranjero.

3 El desempleo de larga duración en España es también más elevado que en otros países y cuenta con un doble impacto negativo. Por un lado, el evidente sobre el colectivo de personas y, por otro, el impacto adicional sobre la productividad agregada de la economía. La duración media del desempleo en España en 2010 fue, según la Organización para la Cooperación y el Desarrollo Económicos (OCDE), de 14,8 meses, frente a una media para los países de la OCDE de 9,6 y de 7,4 meses para los integrantes del G7.

4 Este ajuste ha sido especialmente grave para los trabajadores temporales. Mantenemos una tasa de temporalidad de casi el $25 \%$, mucho más elevada que el resto de nuestros socios europeos. La temporalidad media en la Unión Europea es del 14\%, 11 puntos inferior a la española.

5 La destrucción de empleo durante la última legislatura tiene efectos relevantes sobre el sistema de la Seguridad Social. Desde diciembre de 2007 el número de afiliados ha disminuido en casi 2,5 millones (un 12,5\%). Con mayor razón, si el gasto medio mensual en prestaciones por desempleo en 2007 fue de 1280 millones de $€$, en diciembre de 2011, el gasto ascendió a 2584 millones.

6 Jueces para la Democracia (JD), sin embargo, denuncia una urgencia que no es posible relacionar con unos objetivos a los que no puede hacer frente, y que se utilizan para atacar a la esencia misma del Derecho del Trabajo, intentando despojarle del carácter tuitivo y compensador del tradicional desequilibrio entre las partes de la relación de trabajo. 
De hecho, buena parte de la exposición de motivos se dirige a justificar la concurrencia del presupuesto de extraordinaria y urgente necesidad. La censura que el Tribunal Constitucional (TC) ha realizado en diversas ocasiones a este tipo de norma se encuentra, sin duda, en la base de esa actitud, sin duda conocedora de la jurisprudencia constitucional sobre el tema:

- La utilización del real decreto ley es constitucionalmente lícita en todos aquellos casos en que la gobernación del país requiera de una acción normativa inmediata o en que las coyunturas económicas exijan una rápida respuesta? ${ }^{7}$

- No es arbitraria o abusiva la utilización del decreto ley como respuesta rápida y necesaria ante la persistencia de una coyuntura económica de crisis industrial ${ }^{8}$.

- Para constatar si un decreto ley se dictó en un caso de extraordinaria necesidad, se deben valorar todos aquellos factores que hayan aconsejado al Gobierno a dictarlo?.

- El juicio político sobre la concurrencia del presupuesto habilitante para la utilización de decretos leyes corresponde al Gobierno, sin perjuicio de su posible control jurídico en caso de ausencia de toda justificación ${ }^{10}$.

- A los efectos del control jurídico sobre la extraordinaria y urgente necesidad, en la apreciación de lo que haya de considerarse como tal, es forzoso conceder el peso al juicio puramente político de los órganos a los que incumbe la dirección política del Estado ${ }^{11}$.

A la vista de todo ello, puede aventurarse que la mayoría de las innovaciones aparece adecuadamente justificada; algunas de ellas guardan menos conexión con el supuesto de hecho reseñado y pueden cuestionarse $^{12}$. En todo caso, destáquese lo principal: estamos ante una norma con rango de ley y solo por decisión del TC puede inaplicarse, con independencia de que su entero contenido, como el de cualquier otra norma, haya de interpretarse siempre del modo más acorde con los preceptos constitucionales.

Seguidamente se examina, de manera superficial, cada una de esas normas. Eso impide realizar un estudio profundo sobre cualquier de las instituciones albergadas en ellas, pero a cambio va a permitir

\footnotetext{
7 Sentencia del TC número 29/1986, de fecha 20 febrero, fundamento jurídico 2 (Ponente, Sr. GómezFerrer Morant); Sentencia del TC número 177/1999, de fecha 15 noviembre, fundamento jurídico 3. 8 Sentencia del TC número 29/1986.

9 Sentencia del TC número 29/1982, de fecha 31 de mayo, fundamento jurídico 4 (Ponente, Sr. Velasco Vallejo).

10 Sentencia del TC número 29/1986; Sentencia del TC número 177/1999.

11 Sentencia del TC número 29/1986.

12 Conclusión similar se obtendría examinando el resto de normas reseñadas.
} 
obtener la idea de que (pese a la algarabía empresarial, sindical y política) los cambios poseen bastantes cosas en común: el elenco de materias afectado por las reformas apenas varía, las normas comparten sustancialmente el diagnóstico sobre los problemas y se marcan metas muy similares; por descontado, las divergencias surgen cuando se diseña el modo de recorrer el camino propuesto.

\section{II.REAL DECRETO LEY 10/2010, DE 16 DE JUNIO, SOBRE MEDIDAS URGENTES PARA LA REFORMA DEL MERCADO DE TRABAJO}

Tras un largo período de negociaciones entre los agentes sociales y el Gobierno, en el Boletín Oficial del Estado (BOE) de 17 de junio apareció publicado el importante Real Decreto ley 10/2010, de 16 de junio, sobre Medidas Urgentes para la Reforma del Mercado de Trabajo. Los números del año y de la norma incitan a hablar de «Reforma Diez» y suscitar así, malévolamente o no, el debate sobre su calidad. Cayendo decididamente en la tentación de polemizar, se ofrece aquí una lista de opiniones «breves».

Con el fin de adaptar el sistema normativo español de relaciones laborales a las necesidades del mercado de trabajo y reducir el desempleo, el Real Decreto Ley 10/2010 modifica el Estatuto de los Trabajadores (ET) y las normas concordantes en diversas materias: contratación, flexibilidad interna de las empresas, extinción del contrato, negociación colectiva, intermediación laboral y fomento del empleo, igualdad.

- La norma se separa en muchos temas provenientes de los diversos documentos preparatorios; debemos evitar el error de juzgarla por cosas que no prescribe. iHacemos bien en utilizar esos pre-textos como elementos interpretativos?

- Su extensión y complejidad recomienda que las valoraciones sean también matizadas; descalificaciones globales $\mathrm{O}$ respaldos entusiastas parecen desaconsejables. ¿Por qué optar monolíticamente?

- La concurrencia del presupuesto de la extraordinaria y urgente necesidad es muy discutible en temas cuya virtualidad se posterga, así como provocada por quien goza de iniciativa legislativa y no ha tomado anteriormente medidas para afrontar los problemas ahora acuciantes. iHay cierto fraude constitucional en ello?

- La discusión sobre la subvención de ocho días de indemnización a cargo del Fondo de Garantía Salarial (FOGASA) distrae la atención respecto de lo esencial; la medida quizá no llegue a aplicarse nunca (debe transcurrir más de un año y no haberse

LEGISLACIÓN

DE EMERGENCIA

Y REFORMA

LABORAL EN

ESPAÑA

(2011-2012)

EMERGENCY

LEGISLATION

AND LABOR

REFORM IN

SPAIN

(2011-2012) 
puesto en marcha el Fondo de capitalización). (Para qué llegar a conclusiones numantinas sobre si los ocho días se abonan también en los despidos improcedentes o se acumulan a la tradicional responsabilidad directa en despidos de Pequeña y Mediana Empresa (PYMES)?

- No nos enredemos en discusiones de principio sobre si se ha abaratado el coste del despido. Se ha reducido el preaviso en el objetivo, aligerado los trámites en el colectivo, ampliado la posibilidad de despedir con 33 días, previsto la financiación parcial del FoGASA, etcétera. iHablamos de indemnización por despido o de sus costes?

- Importantísimo que la Ley de Procedimiento Laboral (LPL) y el ET ya no califiquen como nulo el despido objetivo con defectos de forma.

- Será muy, poco o nada relevante el cambio en la causa de despido colectivo (acertadamente parificada con el objetivo) en función de la actitud del intérprete; pero las normas han cambiado y no se habla de necesidad sino de «razonabilidad», además de clarificarse lo que el empleador debe acreditar. iSe ha limitado la norma a postular criterios jurisprudenciales?

- El ET toma las riendas de problemas hasta ahora dejados en manos de la negociación colectiva: descuelgue salarial, duración de los contratos para obra o servicio, conversión en fijos de los temporales reiterados. ¿No debieran hacer los convenios colectivos el mismo examen de conciencia que hay en la exposición de motivos del real decreto ley?

- Dogmáticamente es difícil de entender que el contrato para obra o servicio deje de serlo por el transcurso del tiempo; debe recalcarse que ello no atenúa la necesidad de que concurran autonomía y sustantividad. iHabrá que tramitar un Expediente de Regulación de Empleo (ERE) común cuando se termine la obra o servicio?

- En la novación contractual importante (descuelgue salarial, modificaciones sustanciales, movilidad geográfica) se ha buscado una fórmula sibilina sobre el modo de resolver las discrepancias; pero si la ley no puede imponer el arbitraje obligatorio, tampoco puede exigir a los convenios que lo impongan. $i O$ sí?

- La entrada en juego de las agencias lucrativas de colocación o la apertura de mayores campos de actuación para las Empresas de Trabajo Temporal (ETT) se compatibiliza con el mantenimiento de severas prohibiciones o consecuencias para los casos en que se salta la legalidad. ¿Pierde algo su dignidad o valor el trabajo humano por esa circunstancia? 
- La potenciación de los contratos formativos (algún derecho más para los trabajadores, mayores posibilidades de utilización para las empresas) no reduce la necesidad de que la realidad responda a su contenido formal. ¿Convendría alguna reforma educativa, no solo laboral, en esta cuestión?

- iTiene sentido el mantenimiento de un contrato indefinido como medida de fomento del empleo, con un complejo cuadro de requisitos, solo para permitir su extinción improcedente a menor coste? Si la medida es buena, ipor qué no se generaliza? Y si es inadecuada, ipor qué no se suprime?

- Hace bien el real decreto ley en abordar la suspensión y reducción de jornada por razones económicas, en concordarlo con la protección por desempleo, o en incentivar su utilización para evitar despidos. Algo fuera de contexto parece que se exija aquí acreditar la «necesidad» de la medida y no solo su razonabilidad; y sorprende que no se recupera la cotización homogénea (y rebajada) por contingencias profesionales durante la suspensión. ¿Qué sentido tiene ello?

- Necesariamente, las disposiciones transitorias han de merecer especial atención, suscitando algunas dudas sobre la virtualidad de las nuevas restricciones sobre contratación laboral o el cambio respecto del descuelgue salarial, por ejemplificar. iPuede aplicarse la nueva regulación aunque estén en vigor convenios del viejo sistema?

- Se ha abierto el debate sobre si la «distribución del tiempo de trabajo» puede modificarse de modo sustancial conduciendo a jornadas irregulares respecto de convenios que no la prevén. ¿Puede sostenerse que el artículo 41 del ET ha crecido en extensión pero no en complejidad?

- Las omisiones del real decreto ley respecto de ciertos temas, sistema de negociación, ultraactividad y eficacia de los convenios, control del absentismo, vinculación de los salarios al rendimiento, polivalencia y movilidad funcional, disciplina empresarial, nuevas tecnologías, derechos sindicales y otra larga lista de materias, no debieran lastrar la virtualidad de lo que sí se ha cambiado. ¿Cambiarán las cosas a lo largo de la tramitación parlamentaria?

Agentes sociales, asesores, miembros de la Administración o de la Judicatura, graduados sociales, abogados, directores de personal, representantes de los trabajadores, profesores, prevencionistas, funcionarios y otros muchos colectivos relevantes en el ámbito de las relaciones laborales tenemos ahora el desafío de aplicar la norma de acuerdo con nuestras creencias e intereses. ¿Juego limpio o todo vale? 
En líneas generales, la reforma no constituye una alteración sustancial del modelo de relaciones laborales, aunque supone un importante ajuste en instituciones clave como la contratación o el despido. Se modifican o retocan algunas instituciones importantes, como las modalidades contractuales (obra o servicio y fomento de la contratación indefinida, pero también los formativos) o la extinción del contrato (individual y colectivo) por causas económicas. Se aligera transitoriamente la carga que soportan las empresas respecto de las indemnizaciones por despido, trasladando al FOGASA la responsabilidad del abono de una parte de aquellas. Se flexibilizan las reglas del descuelgue salarial y se da entrada a los sindicatos más representativos, o representativos en el sector, para negociar traslados colectivos o modificaciones sustanciales de las condiciones laborales. Por otra parte, se potencia la negociación colectiva en diferentes ámbitos y el papel de las agencias privadas de colocación; se da entrada a las ETT en la concertación de contratos de puesta a disposición en trabajos o tareas hasta ahora prohibidas. En fin, se establecen medidas de apoyo a la reducción de jornada (con la modificación consiguiente de las normas en materia de desempleo parcial) y a la contratación de jóvenes (hasta 30 años) y de desempleados a través de un paquete importante de bonificaciones.

\section{REAL DECRETO LEY 1/2011, DE 11 DE FEBRERO, DE EMPLEO ESTABLE Y RECUALIFICACIÓN PROFESIONAL}

Esta norma de urgencia estableció un nuevo régimen de bonificaciones a la contratación laboral en los términos siguientes:

1. Vigencia de la medida: un año a partir del 13 de febrero de 2011.

2. Cuantía de la reducción: $100 \%$ en todas las cuotas empresariales a la Seguridad Social en empresas cuya plantilla sea inferior a 250 trabajadores. $75 \%$, si la empresa cuenta con 250 trabajadores o más. Expresamente se incluyen como beneficiarios de estas reducciones los trabajadores autónomos, las sociedades laborales y las cooperativas que hayan optado en sus estatutos por el Régimen General de la Seguridad Social.

3. Duración de la reducción: 12 meses desde la contratación.

4. Requisitos de los trabajadores: desempleo acreditado mediante inscripción ininterrumpida en la oficina de empleo desde, al menos, el 1 de enero de 2011. Ser joven (16-30 años) o estar inscrito como desempleado al menos doce meses en los dieciocho meses anteriores a la contratación.

5. Tipo de contrato: a tiempo parcial, ya sea indefinido o de duración determinada. La jornada ha de estar comprendida entre el 50\% y 
el 75\% de la de un trabajador a tiempo completo comparable, en los términos del artículo 12 del ET. Si se concierta un contrato de duración determinada: La duración inicial prevista ha de ser igual o superior a seis meses. Se excluyen los contratos de interinidad y de relevo.

6. Requisitos de las empresas: la contratación ha de suponer un incremento neto de la plantilla, lo cual se verifica mediante la comprobación de que el promedio de trabajadores en activo durante los noventa días anteriores a la contratación es menor del que resulta en el momento en que esta se produce. El promedio diario de trabajadores con contratos indefinidos o temporales en el período de los noventa días anteriores a la nueva contratación o transformación se calcula dividiendo entre noventa la suma de los contratos indefinidos o temporales que estuvieran en alta en la empresa en cada uno de los noventa días inmediatamente anteriores a la nueva contratación o transformación. Del cómputo se excluyen los contratos indefinidos o temporales que se hubieran extinguido en dicho período por despido disciplinario declarado como procedente, dimisión, muerte, jubilación o incapacidad permanente total, absoluta o gran invalidez del trabajador. El segundo requisito es el mantenimiento del nivel de empleo durante el período de la reducción. La norma no desarrolla este extremo, pero analógicamente debe entenderse que el volumen neto de la plantilla en el momento en que finaliza la reducción de las cuotas ha de ser superior al existente en el momento de la contratación. Llegado el caso, previo requerimiento de las entidades gestoras de la Seguridad Social, la empresa deberá acreditar este extremo. El incumplimiento por las empresas de alguno de estos dos requisitos dará lugar al abono de las cotizaciones correspondientes a las reducciones aplicadas.

7. Transformación de contratos: según la regla general, es posible la transformación de los contratos temporales en indefinidos (ordinarios o de fomento) antes del término del año, sin perder la reducción. Según la regla especial, las empresas que hubieran concertado contratos temporales y, antes del transcurso de un año desde la fecha de celebración, procedieran a su transformación en indefinidos, con la misma jornada u otra superior, tendrán derecho a disfrutar de las bonificaciones de cuotas establecidas en el artículo 10 de la ley 35/2010, de 17 de septiembre ${ }^{13}$. En estos casos, se descontará del período bonificado el ya consumido 
como consecuencia de la aplicación de la reducción prevista en la norma.

8. Trabajadores desempleados que, cumpliendo los requisitos generales, sean discapacitados, tengan acreditada la condición de víctima de violencia de género o de violencia doméstica, o se encuentren en situación de exclusión social: la empresa podrá optar por aplicar las reducciones de cuotas establecidas en el real decreto ley o las bonificaciones reguladas en el capítulo I de la ley 43/2006, de 29 de diciembre, para la mejora del crecimiento y del empleo, si concurren los requisitos correspondientes.

9. Aplicación de otros beneficios al término del año de vigencia del real decreto ley: una vez transcurrido el período de un año de aplicación de la reducción de cuotas, las empresas que hubieran celebrado contratos indefinidos podrán, en su caso, acogerse a la bonificación que pudiera corresponderles de acuerdo a la ley 35/2010, de 17 de septiembre, o al artículo 2 de la ley 43/2006, de 29 de diciembre, exclusivamente por el tiempo que reste de la misma, descontando el período transcurrido de reducción. Esta previsión también se aplica a los contratos temporales concertados con discapacitados, víctimas de violencia de género o de violencia doméstica, o en situación de exclusión social, siempre que cumplan los requisitos exigidos a los trabajadores en general.

\section{REAL DECRETO LEY 5/2011, DE 29 DE ABRIL, SOBRE EMPLEO SUMERGIDO}

El real decreto ley establece un plazo durante el cual los empresarios pueden regularizar la situación de sus trabajadores irregulares. Estas situaciones no serán objeto de sanciones administrativas por el incumplimiento de las obligaciones en relación con la declaración y el reconocimiento de los derechos de los trabajadores afectados, así como en materia de Seguridad Social, estableciéndose la posibilidad de aplazamiento de las deudas con la Seguridad Social en determinadas condiciones.

$\mathrm{Si}$ el empresario se somete al procedimiento de regularización, podrá acogerse a la modalidad de contratación que responda a las características, finalidad y supuestos previstos en la normativa sobre modalidades contractuales.

También se regulan las consecuencias de los eventuales incumplimientos del régimen jurídico de la regularización y se prevé la evaluación y seguimiento de las disposiciones de este real decreto ley, oída la Comisión Consultiva Tripartita de la Inspección de Trabajo y Seguridad Social. 


\section{IV.1. Cuestiones generales}

Como se ha visto, la Unión Europea incentiva actuaciones que ayuden a aflorar empleos irregulares, pero de modo controlado y prudente. Por eso, se comprende tanto la concesión de un plazo breve (desde el 7 de mayo al 31 de julio) para la regularización, cuanto la necesidad de evaluar los efectos de este expediente. En concreto (ver disposición adicional segunda), a partir del 7 de noviembre de 2011 («transcurridos seis meses desde la entrada en vigor») realizará una evaluación y seguimiento de los resultados de las medidas adoptadas. Esa evaluación se realizará oyendo a la Comisión Consultiva Tripartita de la Inspección de Trabajo y Seguridad Social y servirá para adoptar o promover las medidas de adaptación o modificación que resulten adecuadas ${ }^{14}$.

Puesto que se endurecen sanciones, se perdonan infracciones y se altera, con todo ello, el contenido de la Ley de Infracciones y Sanciones en el Orden Social (LISOS), conviene tener muy presente que las infracciones cometidas hasta el 31 de julio de 2011 se sancionarán conforme a las cuantías y se someterán al régimen de responsabilidades vigente con anterioridad a dicha fecha (disposición transitoria única).

\section{IV.2. Incumplimientos regularizables}

- El «proceso voluntario de regularización» se describe en el artículo primero del Real Decreto Ley 5/2011 y debe ser interpretado de forma restrictiva:Pueden acogerse al mismo «los empresarios que ocupen trabajadores de manera irregular». Parece razonable entender que aquí tienen cabida las cooperativas respecto de sus socios-trabajadores y cualesquiera empleadores respecto de sus asalariados, pero no los autónomos o quienes (servidores domésticos) vienen ellos mismos obligados a promover su afiliación y alta.

- La dicción normativa excluye la posibilidad de que las empresas regularicen situaciones de quienes han sido sus empleados pero han dejado de serlo. Sin embargo, sí entran los períodos pretéritos de actividad desempeñados por antiguos trabajadores y que vuelvan a ser contratados por la empresa; lo importante es que todo refiera a quienes son trabajadores al momento de interesarse la empresa por la regularización.

- La irregularidad que puede aflorar solo refiere a una cuestión: «no haber solicitado su afiliación inicial o alta en la Seguridad Social», quedando al margen todas las demás actuaciones ilegales 
en materia de contrato de trabajo, libertad sindical, prevención de riesgos laborales, empleo, etcétera.

- Hay un plazo estricto para que las empresas puedan acogerse al beneficio de referencia: desde el 7 de mayo hasta el 31 de julio de 2011.

Asimismo, el camino para acceder a esta normalización es único y viene indicado en el artículo 2.1 del real decreto ley:

- Las empresas «deberán solicitar» la subsunción de las irregularidades que deseen en el ámbito aplicativo del real decreto ley, sin que sea posible la actuación de oficio (a cargo de la Tesorería General de la Seguridad Social o la Inspección), ni surte idénticos efectos la eventual denuncia de terceros (trabajadores afectados, comités de empresa, etcétera).

- El empleador ha de instar «el alta de los citados trabajadores», es decir de aquellos respecto de los cuales se omitió, con independencia al tiempo transcurrido en esas condiciones o cualquier otra circunstancia.

- Coordenadas lógicas para el cumplimiento de ese deber instrumental es que se lleve a cabo «en el correspondiente régimen de la Seguridad Social» (no se limita al General) y «dentro del plazo señalado» (antes de 1 de agosto).

\section{IV.3. Efectos de la regularización}

La esencia de la «regularización» consiste en que cuando la empresa insta el alta del trabajador, pese a hacerlo tardíamente, no será sancionada administrativamente por el incumplimiento de las obligaciones en relación con la declaración y el reconocimiento de los derechos de los trabajadores afectados. Tampoco se está concediendo una amnistía que implique el perdón de las deudas de cotización o la ausencia de responsabilidades en el pago de prestaciones, sino simplemente un supuesto de exención de responsabilidad administrativa.

Aunque es cierto que el real decreto ley debiera haber sido bastante más explícito en esta cuestión, que así sea puede afirmarse tanto por una interpretación teleológica cuanto por un argumento sistemático, se contempla la posibilidad de aplazamiento de las deudas con la Seguridad Social, luego la obligación de cotizar retroactivamente no desaparece. Así las cosas, hay que realizar una triple observación.

a. Seguridad Social.-El ingreso de las cotizaciones a la Seguridad Social y por los conceptos de recaudación conjunta correspondientes será en las cuantías «que procedan con arreglo a la legislación vigente de la Seguridad Social». No se ha precisado un límite retroactivo, por lo que es 
posible regularizar actividades no declaradas y que vienen desarrollándose desde hace más de cuatro años, lo que podrá comportar la prescripción parcial de la obligación de cotizar. Pese al tardío cumplimiento patronal del alta, el importe a satisfacer «podrá ser objeto de aplazamiento en los términos reglamentariamente establecidos» (artículo 2.2).

b. Sanciones administrativas.- Respecto a los trabajadores afectados por la regularización, la ausencia de alta o las irregularidades asociadas (comenzando por la ausencia de cotización) no podrán ser objeto de las sanciones administrativas previstas en la LISOS. Importantísimo es advertir que la exclusión infractora solo concierne a «las infracciones tipificadas en dicho texto legal relacionadas con tales situaciones»; nada impide la sanción por irregularidades en materia de riesgos laborales, atentados a la dignidad e intimidad, impago salarial, etcétera.

c. Actuaciones en curso.- La mayor ventaja del proceso de regularización (exención de responsabilidad administrativa) desaparece cuando, al momento de solicitar la empresa el alta, ya se hubiere iniciado una actuación en la empresa en materia de seguridad social, que tenga por objeto o afecte a las situaciones de hecho referidas en dicho apartado o hubieren tenido entrada en la Inspección de Trabajo y Seguridad Social denuncias, reclamaciones o escritos de cualquier naturaleza relacionados con tales situaciones en la misma empresa, o demandas ante la Jurisdicción Social.

d. Vinculación laboral.- Las consecuencias y peculiaridades del proceso de regularización aumentan cuando se enfoca hacia el nexo laboral. Los empleadores deben formalizar un contrato de trabajo, indicando en él la circunstancia de la regularización.

- Se admite cualquier modalidad contractual indefinida o temporal o de duración determinada, incluidos los contratos formativos, siempre que se reúnan los requisitos exigidos para su celebración.

- Cuando se trate de contratos de carácter temporal o de duración determinada su duración inicial prevista no podrá ser inferior a seis meses, desde la fecha de solicitud del alta en la Seguridad Social.

- Se declara inaplicable el artículo 15.2 del ET sobre la adquisición de la condición de fijos por parte de trabajadores cuyas empresas no los hubieren dado de alta transcurrido un tiempo equivalente al máximo que hubiera podido tener el período de prueba (artículo 4.2). 


\section{IV.4. Sanciones específicas}

Del mismo modo que el real decreto ley evita la imposición de sanciones administrativas, él mismo es fuente de nuevas infracciones para estimular el cumplimiento de las obligaciones inherentes al proceso de regularización:

- Los empresarios que se acojan indebidamente ( «sin reunir los requisitos establecidos») al proceso o los que extingan el contrato de los trabajadores regularizados «antes de seis meses, cualquiera que fuera la modalidad de contratación utilizada» perderán automáticamente el derecho a acogerse a sus beneficios y efectos.

- Las empresas en cuestión deberán reintegrar las ayudas, bonificaciones y, en general, los beneficios derivados de la aplicación de los programas de empleo, obtenidos como consecuencia de esta contratación.

- Lo anterior no será aplicable a las extinciones por despido disciplinario declarado como procedente, o por dimisión, muerte, jubilación o incapacidad permanente total, absoluta o gran invalidez del trabajador.

- Los empresarios que incumplan el régimen jurídico de la regularización deberán proceder al ingreso de las cuotas de Seguridad Social que procedan.

- Asimismo, tales empresas podrán ser sancionadas conforme a la LISOS.

\section{REAL DECRETO LEY 7/2011, DE 10 DE JUNIO, SOBRE NEGOCIACIÓN COLECTIVA}

Fracasado el diálogo social, mediante Real Decreto Ley 10/2010 de fecha 16 de junio, se aprobaron numerosas medidas para la reforma del mercado de trabajo. Tras la pertinente singladura parlamentaria, la norma de excepción se convirtió en ley 35/2010 de fecha 17 de septiembre, que reiteró la voluntad de respetar el acuerdo a que llegasen los interlocutores sociales. Sin embargo, se introdujo una previsión que deseaba estimular la adopción de las modificaciones tantas veces postergadas.

De su disposición adicional vigésima primera ${ }^{15}$ deriva la intención de conciliar el proceso de diálogo social bipartito con las competencias

15 «El Gobierno promoverá las iniciativas legislativas que correspondan para la reforma de la negociación colectiva en los términos que, en ejercicio de la autonomía colectiva, sean acordados y les sean requeridos por los interlocutores sociales en el proceso de negociación bipartita que actualmente desarrollan conforme a lo pactado en el Acuerdo para el Empleo y la Negociación Colectiva, 2010, 2011 y 2012». 
normativas de los órganos constitucionales: la ley ordena al Gobierno que active la modificación del título III del ET, pero le indica al Poder Ejecutivo que actúe conforme al acuerdo que alcancen quienes vienen participando en el proceso de diálogo social. Hay aquí un inmejorable ejemplo de (previsión sobre) legislación negociada, donde el legislador, los agentes sociales y el Gobierno han de representar acertadamente su papel para que se alcance el éxito final.

Pero no se agotaban ahí las prescripciones de la ley 35/2010 sino que, escarmentada ya por la demora de las conversaciones de sindicatos y patronal, al tiempo que urgida por diversas instancias internacionales, añadió una segunda y cautelar previsión: en defecto de acuerdo en el proceso de negociación bipartita, en un plazo de seis meses a contar desde la entrada en vigor de esta ley, el Gobierno, previa consulta con las organizaciones empresariales y sindicales, adoptará las iniciativas que correspondan ${ }^{16}$.

Tras diversos avatares que no vienen al caso, desde febrero hasta mayo de 2011 los agentes sociales mantuvieron numerosas sesiones de trabajo e intercambiaron diversos documentos, pero sin llegar a un acuerdo concreto. Transcurrido con creces el plazo previsto por la ley 35/2010, y fracasadas las expectativas de que las negociaciones terminaran en un acuerdo bipartito, finalmente el Gobierno decidió activar la responsabilidad que subsidiariamente le había conferido el mandato legal. De hecho, el preámbulo del Real Decreto Ley 7/2011 justifica esa intervención («la reforma de la negociación colectiva no puede esperar más tiempo») mencionando los mismos problemas que se detectan desde que se aprobara el título III: normativa que presenta disfunciones y que desde hace años no ha sido objeto de modificación, falta de entendimiento entre los interlocutores sociales y situación de la economía.

\section{V.1. Una reforma «impuesta»}

Ha de llamarse la atención sobre el dato de que tras tantos años de fallidos intentos para modificar el régimen estructural de nuestros convenios colectivos, la modificación haya tenido que llevarse a cabo a través de una norma con innegables visos de unilateralidad: no dimana (como prefería la ley 35/2010) de una propuesta procedente de los

16 El tercer tramo de la disposición adicional de la ley 35/2010 realizaba una enumeración ejemplificativa de los aspectos ("entre otros») que debería abordar la iniciativa subsidiaria en cuestión. Es decir, si el diálogo social no fructificase a lo largo de todo un semestre, se le encargaba al Gobierno que afrontase la regulación de las siguientes materias: «la definición de mecanismos de articulación de la negociación colectiva, su papel como procedimiento de fijación de las condiciones laborales y de determinación de las políticas de empleo, su capacidad de adaptación a las necesidades de los trabajadores, las empresas y sectores productivos y la mejora de la productividad, así como todos aquellos elementos e instrumentos que relacionados con los objetivos señalados configuran el actual sistema de negociación colectiva».

LEGISLACIÓN

DE EMERGENCIA

Y REFORMA

LABORAL EN

ESPAÑA

(2011-2012)

EMERGENCY

LEGISLATION

AND LABOR

REFORM IN

SPAIN

(2011-2012) 
agentes sociales, tampoco de un proyecto de ley (sino de un excepcional real decreto ley) y su respaldo político es exiguo (la convalidación parlamentaria se consiguió por una ajustada cifra de Diputados).

En absoluto esos avatares cuestionan, sino todo lo contrario, la validez democrática, constitucional o formal de una norma con rango de ley. Tema diverso es que cumpla con las exigencias constitucionales del caso (presupuesto habilitante, materia abordada) o que su contenido suscite una u otra valoración. Pero el carácter unilateral de la regulación posee otra dimensión que no debe perderse de vista: la mayoría de las innovaciones acogidas por el Real Decreto Ley sobre Negociación Colectiva solo serán operativas cuando los propios interlocutores sociales las hagan suyas: cuando se negocien los nuevos convenios, se noven las unidades de negociación, se ponga en juego todo el potencial de competencias asignadas a las Comisiones Paritarias, se lleven a la práctica las posibilidades de flexibilidad interna, etcétera. ¿En qué medida pueden llevarse a los periódicos oficiales, a las empresas, órganos de solución de conflictos, Comisiones Paritarias, sindicatos o comités de empresa las nuevas orientaciones sin una actitud receptiva por parte de todo ese entramado? ¿Bastará con las prescripciones de referencia para reconducir el modelo de negociación y administración de convenios? Es decir: no debe minimizarse el riesgo de que los interlocutores sociales marginen en la práctica el contenido de las nuevas prescripciones, sea por estrategia, sea por discrepancia, sea por otros motivos.

Dicho de otro modo: el presupuesto principal e implícito para la operatividad de la reforma sobre negociación colectiva es que se produzcan acuerdos, sea en el ámbito de negociación correspondiente, sea a escala empresarial. Sin una sintonía aceptable entre previsiones normativas y autonomía colectiva pocos frutos podrán brotar de las nuevas ramas del árbol, por decirlo metafóricamente.

\section{V.2. Una reforma «provisional»}

La decisión de tramitar el texto del Real Decreto Ley sobre Negociación Colectiva como proyecto de ley nos sitúa (en una práctica que viene repitiéndose y que presenta numerosos inconvenientes) ante una nueva reforma bifásica en la que el real decreto ley actúa como una especie de explorador o guía que va allanando el terreno a la expedición parlamentaria.

El debate de convalidación ha permitido comprobar que parte de los apoyos necesarios se condicionaron a la ulterior incorporación de novedades en diversos aspectos: alcance de la prioridad asignada a los convenios de empresa, primacía del ámbito autonómico de negociación 
colectiva, vinculación de los salarios a índices diversos al Índice de Precios al Consumidor, etcétera.

De todos modos, conviene no exagerar la provisionalidad. Primero, porque el grueso de las reformas ya introducidas previsiblemente no se verá afectado. Segundo porque la virtualidad de los cambios no precisa de desarrollo reglamentario, salvo cuestiones de detalle, sino de la voluntad (generalmente pactada) para convertirlos en realidad. Tercero, porque la propia inestabilidad política, paradójicamente, reforzó el valor de las novedades introducidas porque las Cortes Generales fueron disueltas antes de que hubiese visto la luz el nuevo texto legal.

\section{V.3. Un envoltorio normativo cuestionable}

Un sector destacado de la doctrina viene cuestionando la utilización del real decreto ley para incidir en cuestiones que afectan directamente a la libertad sindical. Puesto que la negociación colectiva se integra en el contenido esencial de la libertad sindical y la misma, en cuanto derecho fundamental, ha de regularse mediante Ley Orgánica podría postularse que la negociación colectiva no admite una regulación procedente de normas - de excepción o no- privadas de carácter «orgánico». Estaríamos ante una disposición invasora de esa reserva e inconstitucional por razones formales, pues no puede regularse el régimen general de los derechos, deberes y libertades, a través del decreto ley ${ }^{17}$.

Según esta tesis, estaríamos en el campo reservado a la Ley Orgánica, en el caso de las normas que establezcan restricciones de los derechos y libertades fundamentales o los desarrollen de modo directo, no las que incidan indirectamente sobre su ámbito y límites ${ }^{18}$. Como se sabe, las reservas de Ley Orgánica son únicamente aquellas expresamente establecidas por la Constitución española (CE) en sus artículos 81 y conexos - reservas de carácter material y no formal—, de manera que la normación de las materias ajenas a las mismas no goza de la fuerza pasiva inherente a dicha clase de leyes aunque se incluya en ellas ${ }^{19}$. Se excluye de la reserva de Ley Orgánica la regulación de aspectos que únicamente afectan a elementos no necesarios de los derechos fundamentales sin incidir directamente sobre su ámbito o límites ${ }^{20}$.

En esas condiciones, si se considera que hay una invasión contraria a la Ley Fundamental, debiera realizarse similar valoración crítica respecto

17 Sentencia del TC número 3/1988, de fecha 21 de enero, fundamentos jurídicos 5, 6 y 7 (Ponente, Sr. López Guerra).

18 Sentencia del TC número101/1991, de fecha 13 de mayo, fundamento jurídico 2 (Ponente, Sr. Díaz Eimil); Sentencia del TC número 142/1993, de fecha 22 de abril, fundamento jurídico 2 (Ponente, Sr. Rodríguez-Piñero y Bravo Ferrer).

19 Sentencia del TC número 224/1993, de fecha 1 de julio, fundamento jurídico 2 (Ponente, Sr. Rodríguez Bereijo).

20 Sentencia del TC número 142/1993.

LEGISLACIÓN

DE EMERGENCIA

Y REFORMA

LABORAL EN

ESPAÑA

(2011-2012)

EMERGENCY

LEGISLATION

AND LABOR

REFORM IN

SPAIN

(2011-2012) 
del propio ET, pues su título III carece de la condición de norma orgánica. Por el contrario, si se entiende que lo prevalente es el desarrollo de la negociación colectiva (artículo 37 y no 28 de la CE) tales obstáculos desaparecen, como aquí se piensa.

\section{V.4. Unos presupuestos habilitantes dudosos}

La aprobación de una norma sin el previo éxito del diálogo social es considerada por alguna de las partes implicadas como una ruptura de las reglas implícitas sobre el modo en que habrían de producirse las variaciones en el sistema jurídico-laboral. Sin embargo, es claro que desde una estricta consideración jurídica, el Gobierno no venía obligado a seguir tan deseable método y que la Constitución (especialmente artículos 97 y 86) ampara su facultad normativa de carácter unilateral.

Más discutible resulta determinar si existe el presupuestode extraordinaria y urgente necesidad requerido en el artículo 86 del texto constitucional a fin de que el Poder Ejecutivo pueda alumbrar una norma con rango de ley, sin perjuicio de su ulterior convalidación por el Congreso de los Diputados. Las razones apuntadas en la exposición de motivos del Real Decreto Ley sobre Negociación Colectiva quieren justificar la pertinencia de su contenido, pero no en todos los temas abordados parece haberse conseguido, además de que determinadas modificaciones (nada secundarias) aparecen despegadas de la justificación pertinente. Inevitablemente, las dudas (sobre la extraordinaria urgencia) se acentúan cuando se examinan algunas concretas innovaciones o modificaciones, aunque es arriesgado afirmar que ha existido un uso abusivo y global de la excepcional posibilidad reguladora en cuestión que, además, tendría que ser apreciado por el $\mathrm{TC}^{21}$.

Da la impresión de que el Gobierno ha abusado, una vez más, del expediente normativo en cuestión; la paralela tramitación de una importante modificación sobre pensiones de jubilación y otras prestaciones de Seguridad Social ejemplifica de modo inmejorable cuanto se quiere indicar. Existen mecanismos para aprobar Leyes complejas por el procedimiento de urgencia. El fracaso del proceso de concertación

21 Profundizando en esta reflexión, debe subrayarse que, aparentemente hay una contradicción en la exposición de motivos del Real Decreto Ley sobre la Negociación Colectiva. Si los problemas afrontados por la norma vienen de muy atrás (el sistema presenta «disfunciones que le restan eficiencia y, particularmente, capacidad de adaptación a las condiciones cambiantes de la economía y del empleo y del propio modelo de relaciones laborales") y esos defectos se han detectado con antelación (dichas disfunciones «han sido diagnosticadas hace tiempo por todos aquellos sujetos que de una u otra manera actúan en la negociación colectiva: los propios interlocutores sociales, los académicos y los expertos y los poderes públicos»), da la impresión de que la necesidad de abordarlos por la vía de urgencia («la reforma de la negociación colectiva no pueda esperar más tiempo") viene a estar - en buena medida - provocada por la persistente pasividad de los poderes normativos. Sea por aguardar los resultados del diálogo social, por considerar que el modelo aún tenía recorrido, o por cualesquiera otras causas, lo cierto es que la necesidad de cambio existe pero su urgencia deriva de no haberla afrontado con antelación. 
social y el deseo de afrontar la materia no parecen argumentos bastantes para haber forzado el acudimiento al real decreto ley.

\section{V.5. Una figura discutible}

LEGISLACIÓN

Probablemente deslumbrado por el modo en que finalizó uno de los conflictos laborales más graves de nuestra moderna historia (el de los controladores aéreos), el legislador de urgencia concede un papel importantísimo a la figura de los medios de solución extrajudicial de conflictos colectivos que se imponen cuando la disputa se enquista, en particular al arbitraje obligatorio.

Esa vía está pensada, conforme a la jurisprudencia constitucional, para casos excepcionales de huelgas en servicios esenciales de la comunidad, en los que la autoridad gubernativa no puede imponer la reanudación del trabajo, aunque sí puede instituir un arbitraje obligatorio como vía de terminación de la huelga ${ }^{22}$. El recurso al laudo impuesto cuando un conflicto de intereses se enquistaba fue considerado contrario a la Ley Fundamental, por opuesto a la libertad sindical y al derecho a la negociación colectiva.

Pensar en este expeditivo camino para desatascar los bloqueos de negociación, las polémicas sobre la ultraactividad del convenio, las decisiones sobre flexibilidad interna, los descuelgues, la adopción de criterios por parte de las Comisiones Paritarias u otras cuestiones parece una decisión errónea. Desde luego, que ello se haga solo durante un tiempo, o que se imponga la forzosidad del expediente arbitral a los propios acuerdos y convenios puede atenuar la inconstitucionalidad en su dimensión cuantitativa o cualitativa, pero por ello no deja de existir. Ello, al margen de la torpeza que comporta la introducción de elementos coactivos en un terreno dominado por la autonomía de la voluntad; los propios sistemas de solución extrajudicial de conflictos pueden ver minada su credibilidad al ser obligados a desempeñar ese papel de bomberos a la fuerza.

\section{V.6. Núcleos básicos}

Pese a que se han respetado las paredes maestras del título III, conviene no minimizar el calado de las modificaciones que han acabado afectando, en mayor o menor medida a los elementos básicos del sistema: sujetos, dinámica, objeto y estructura interna. Como breve inventario valga lo siguiente: 
- SujeTOS: se han modificado las reglas sobre legitimación a nivel de empresa (primacía de las secciones, convenios-franja) o superior (redefiniendo la representatividad de las asociaciones patronales). Se ha retocado la composición de la Comisión Negociadora y llevado a la ley algunas reglas que aparecían reconocidas como criterios jurisprudenciales. Se ha contemplado y resuelto la imposibilidad negocial derivada de la ausencia de interlocutores legitimados («sectores vírgenes»). Se potencia enormemente el papel de la Comisión Paritaria.

- ARTICUlaCión: se revisan las reglas sobre estructura y concurrencia (permitiendo que los convenios de empresa asuman mayores funciones; postergando el papel de los provinciales; simplificando, para ceñirlo al convenio de ámbito autonómico, la posibilidad de que un convenio sectorial afecte a otro superior). Se aborda expresamente el caso de los convenios de empresas en red (o grupos). Se flexibilizan ciertos descuelgues empresariales.

- CONTENIDO: el aumento de materias que obligatoriamente debe albergar todo convenio también potencia sus posibilidades reguladoras; es llamativo que se acepte la validez de los pactos provisionales que se logren al hilo del procedimiento de negociación.

- DiNÁMICA: se topan los plazos durante los que puede negociarse el convenio; se reordena la prórroga y ultraactividad.

\section{V.7. Objetivos}

EL Real Decreto Ley sobre la Negociación Colectiva respeta los trazos básicos e identificativos del sistema de negociación colectiva (fuerza normativa, eficacia general; sindicalización de los supraempresariales; máxima libertad para fijar los ámbitos aplicativos personales o temporales; posibilidad de concurrencia; control administrativo y judicial; registro y publicidad públicos; etcétera), pero introduce diversas modificaciones que persiguen «más y mejor negociación colectiva, más ordenados y mejores convenios colectivos». A tal efecto la propia norma subraya sus tres objetivos principales:

- Mejor ordenación de la negociación colectiva: más cercana a la empresa y más adaptada a cada sector de actividad económica.

- Mayores niveles de dinamismo y agilidad: capacidad de adaptabilidad a los cambios económicos y sociolaborales (flexibilidad), en procedimientos y contenidos, contemplando los derechos de los trabajadores (seguridad). 
- Adaptación del sistema a nuevas realidades empresariales: nuevas reglas de legitimación, favorecimiento de la flexibilidad interna negociada.

Teniendo en cuenta esas finalidades (cuya relevancia a la hora de interpretar el alcance de los preceptos huelga resaltar), la reforma del sistema de negociación colectiva se asienta sobre tres ejes básicos: la estructura de la negociación colectiva y la concurrencia de convenios colectivos; las nuevas reglas sobre el contenido y vigencia de los convenios colectivos; una mejor y más completa definición de los sujetos que han de negociar los convenios y de las reglas de legitimación en cada caso, según el ámbito de que se trate.

\section{V.8. Otras cuestiones}

La norma finalmente publicada en el BOE, reformando el título III del ET, ocupa dieciocho de sus páginas, aunque algo más de siete se dedican a la exposición de motivos y las tres últimas abordan cuestiones instrumentales (Consejo de Relaciones Laborales y de Negociación Colectiva, derogaciones, transitoriedades, información telemática, etcétera). El resto del articulado es el que confiere nueva redacción a los artículos en cuestión.

Pese a haberse orillado inicialmente algunas cuestiones (absentismo, productividad) o atenuado las previsiones sobre otras (ultraactividad, concurrencia), el real decreto ley se marca objetivos, instrumenta soluciones y adopta decisiones concretas. De sus innovaciones destila una clara potenciación del asociacionismo (sindical, patronal), una notable potenciación de la autonomía colectiva (curiosamente, al incrementarse las exigencias legales sobre los convenios, para que puedan asumir nuevas funciones) y una actuación acorde con la tan manida flexiseguridad. Se mantiene el horror vacui (temor a que queden vacíos regulatorios allí donde venía habiendo norma sectorial). Se introducen ingredientes dinámicos en el modelo de negociación (adopción de acuerdos parciales en el procedimiento de negociación, fijación de plazos máximos para las distintas fases de la gestación convencional, posibilidad de alterar un convenio desde la Comisión Paritaria, adaptabilidad a la empresa, etcétera).

\section{REAL DECRETO LEY 10/2011, DE 26 DE AGOSTO, SOBRE EMPLEO Y DESEMPLEO}

En el BOE de 30 de agosto de 2011 apareció publicado el Real Decreto Ley 10/2011, de 26 de agosto, de Medidas Urgentes para la Promoción del Empleo de los Jóvenes, el Fomento de la Estabilidad en el Empleo y el Mantenimiento del Programa de Recualificación Profesional de

LEGISLACIÓN DE EMERGENCIA Y REFORMA

LABORAL EN ESPAÑA

(2011-2012)

EMERGENCY

LEGISLATION

AND LABOR REFORM IN

SPAIN

(2011-2012) 
las Personas que Agoten la Prestación por Desempleo. La vorágine en que se encuentra inmerso el ordenamiento laboral, el ambiente de fin de legislatura, la mayor relevancia mediática de otros temas (reforma constitucional, evolución de la prima de riesgo de nuestra deuda soberana, situación de Libia, clima pre electoral, etcétera) y la ausencia de respaldo (tanto político cuanto de los agentes sociales) han hecho que pase desapercibida. En seguida se ofrece una visión general, sin entrar en detalles y pensando en la repercusión práctica de las novedades ${ }^{23}$.

Lamentablemente, con ella se quiebra una tendencia que parecía bien asentada en nuestro ordenamiento: la apuesta por contratos más estables (de contenido flexible). Ante el pavoroso escenario de desempleo, nuestras normas vuelven a la idea de que «más vale un trabajador con empleo temporal que sin actividad alguna»; aunque no sea esta la sede para profundizar en la materia, quede constancia de que sería mucho más beneficioso conseguir que la práctica corriera paralela al diseño teórico de las normas. Está pendiente toda una pedagogía (hacia empresas, trabajadores, asesores, jueces, inspectores, profesores) respecto de las innovaciones introducidas en los últimos años; en lugar de ello, ahora se da marcha atrás y el modelo resulta cada vez más incomprensible y disfuncional. Por este camino, acabaremos teniendo no solo una mala praxis (contratos sistemáticamente temporales, decisiones apriorísticamente enemigas de los cambios) sino también un diseño normativo caprichoso (hecho a impulsos, sin obedecer a principios claros).

\section{VI.1. Contrato para la formación y el aprendizaje}

Se quiere propiciar la cualificación profesional de los trabajadores en un régimen de alternancia de actividad laboral (retribuida por la empresa) con actividad formativa externa (a cargo del sistema de formación profesional para el empleo o del sistema educativo). Pero sobre esa finalidad específica prima la coyuntural de mejorar las oportunidades de empleo y formación de los jóvenes en situación de desempleo. Tras los años de expansión («burbuja inmobiliaria») y del dinero fácil, ha quedado un panorama desolador de legiones juveniles desempleadas

23 Varias normas con rango de ley han sido modificadas de uno u otro modo; he aquí su descripción mínima: ET: se cambia el artículo 11.2, derogando el contrato para la formación e introduciendo un nuevo contrato para la formación y el aprendizaje; ley 39/2010, de 22 diciembre, de Presupuestos Generales del Estado para el año 2011: se modifica la cotización de diversas modalidades contractuales; ley 35/2010, de 17 de septiembre, de Medidas Urgentes para la Reforma del Mercado de Trabajo: se aplaza la constitución del Fondo de capitalización; ley 35/2010, de 17 de septiembre: se retoca la obligación del FOGASA de abonar parte de la indemnización en ciertos despidos; ley 12/2001, de 9 de julio, de Medidas Urgentes de Reforma del Mercado de Trabajo para el Incremento del Empleo y la Mejora de su Calidad: se amplía la posibilidad de transformar contratos temporales en fijos de fomento de la contratación indefinida; ET: suspensión de la vigencia del artículo 15.5 sobre conversión de los contratos temporales y sucesivos en fijos o indefinidos; Real Decreto Ley 1/2011, de 11 de febrero, de Medidas Urgentes para Promover la Transición al Empleo Estable y la Recualificación: prórroga de su vigencia; ley 32/2010, de 5 de agosto, por la que se Establece un Sistema Específico de Protección por Cese de Actividad de los Trabajadores Autónomos: para introducir leves mejoras. 
y sin cualificar (nada menos que el 60\% de los menores de 25 años no poseen siquiera el título de graduado en Educación Secundaria Obligatoria (ESO)).

Una vez más, quizá buscando la comparación con el país de éxito, nuestro legislador afirma inspirarse en el sistema alemán de formación dual; se persigue superar la tradicional distinción entre teoría y práctica, asumiendo la alternancia entre actividad laboral retribuida y actividad formativa «oficial» además de, por descontado, mejorar el claro fracaso de la figura nacional: apenas un $1 \%$ de las contrataciones realizadas se viene encauzando a través de esta modalidad.

Por todo ello, hay un cambio de denominación (el añejo contrato de aprendizaje se reconvirtió en «contrato para la formación» y ahora se unen las dos rúbricas), adaptando la vertiente formativa al sistema de formación profesional (cualificaciones profesionales, familias profesionales, certificados de profesionalidad).

- Edad del trabajador: mayores de 16 y menores de 25, pero sin tope máximo para «personas con discapacidad». Hasta el 31 de diciembre de 2013 cabe la contratación de menores de 30 años.

- Requisito adicional y negativo de los trabajadores: que carezcan de la cualificación profesional reconocida por el sistema de formación profesional para el empleo o del sistema educativo requerida para concertar un contrato en prácticas.

- Prohibición subjetiva absoluta: expirada su duración, el trabajador no podrá ser contratado bajo esta modalidad por la misma o distinta empresa.

- Prohibición subjetiva relativa: cuando el puesto de trabajo ya haya sido desempeñado por el trabajador en la misma empresa por tiempo superior a doce meses.

- Requisitos de las empresas: no existen. Ha desaparecido la habilitación a la negociación colectiva para establecer el número o porcentaje máximo de contrataciones posible en cada empresa, o los puestos de trabajo objeto del contrato. Se abre así un campo para la discusión sobre el papel que puede jugar el convenio en esta materia, especialmente si se considera que el objetivo de crear empleo es absolutamente prioritario en la norma de urgencia y que cualquier limitación convencional podría constituir un obstáculo en aras a la consecución del indicado objetivo.

- Limitación de contrataciones: desaparece el llamamiento a la negociación colectiva para establecer, en función del tamaño de la plantilla, el número máximo de contratos a realizar y, en su caso, los puestos de trabajo objeto del contrato.

LEGISLACIÓN DE EMERGENCIA Y REFORMA

LABORAL EN ESPAÑA

(2011-2012)

EMERGENCY

LEGISLATION

AND LABOR

REFORM IN

SPAIN

(2011-2012) 
- Duración: mínimo un año y máximo dos. Posible prórroga de otros 12 meses por necesidades del proceso formativo del trabajador en los términos que se establezcan reglamentariamente; por necesidades organizativas o productivas de acuerdo con lo dispuesto en convenio colectivo; cuando se celebre con trabajadores que no hayan obtenido el título de graduado en ESO. Los cambios en relación con el régimen preexistente son relevantes: se eleva de 6 meses a un año la duración mínima y desaparece la posibilidad reconocida a los convenios de ampliar su duración; nuevamente parece que estamos ante normas de orden público absoluto. Tiempo no computable a efectos de duración máxima: incapacidad temporal, riesgo durante el embarazo o lactancia, maternidad o paternidad, adopción o acogimiento.

- Formación: ha de recibirse directamente en un centro formativo previamente reconocido para ello por el sistema nacional de empleo.

- Trabajo: la actividad laboral debe estar relacionada con las actividades formativas (la exposición de motivos dice que «la persona trabajadora realizará un trabajo efectivo en una empresa directamente relacionado con la formación que está recibiendo, lo que favorecerá una mayor relación entre esta y el aprendizaje en el puesto de trabajo»).

- Simultaneidad: las acciones formativas deben comenzar en los primeros cuatro meses desde la celebración del contrato. Se trata de un plazo para que tanto la práctica cuanto el desarrollo reglamentario cuentan con cierto margen de maniobra.

- Tiempo de trabajo: compatible con actividades formativas y como máximo el $75 \%$ de la jornada máxima (legal o convencional). Precedentemente el tiempo mínimo dedicado a la formación era del $15 \%$, por lo que parece que se quiere potenciar la formación sin incrementar por ello los costes empresariales. De hecho, la combinación del tiempo máximo de trabajo efectivo y el tiempo dedicado a la formación desembocan en un abaratamiento de los costes empresariales, sin necesidad de aplicar el complejo régimen jurídico del contrato a tiempo parcial, con el que guarda ciertas similitudes como se deduce de la prohibición de realizar horas extraordinarias (salvo en caso de fuerza mayor). Para contrarrestar esta mayor flexibilidad, el contrato para la formación y el aprendizaje no podrá utilizarse para trabajos nocturnos ni a turnos.

- Retribución: proporcional al tiempo de trabajo efectivo; respetando el Salario Mínimo Interprofesional, el convenio colectivo puede preverla. 
- Continuidad: si al término del contrato formativo se incorpora el trabajador a la empresa no cabe nuevo período de prueba y el tiempo transcurrido computa a efectos de antigüedad.

- Seguridad Social: se cubren todas las contingencias (incluso desempleo), y FOGASA.

\section{VI.2. Otras cuestiones}

Una de las novedades de la Reforma Laboral de 2010 era este «Fondo de capitalización para los trabajadores, mantenido a lo largo de su vida laboral, por una cantidad equivalente a un número de días de salario por año de servicio a determinar». Debía haber estado operativo a partir de enero próximo, siendo su misión abonar a cada trabajador las cantidades acumuladas a su favor en ciertos supuestos (jubilación, despido, movilidad geográfica, actividades formativas).

Ahora se constata que será inviable porque, según un informe elaborado por seis expertos nombrados por el Gobierno su implantación exigiría recaudar 7500 millones de euros anuales, lo cual supondría incrementar en tres puntos las cotizaciones empresariales, justamente cuando se desea lo contrario. Pese a todo, el Gobierno insiste en el modelo y se encomienda a sí mismo el desarrollo «durante el primer semestre de 2013 [de] un proceso de negociación con las organizaciones empresariales y sindicales más representativas sobre la conveniencia y oportunidad de aprobar un proyecto de Ley» en los mismos términos que los contemplados en la disposición adicional que se deroga: un «Fondo de capitalización para los trabajadores, mantenido a lo largo de su vida laboral, por una cantidad equivalente a un número de días de salario por año de servicio a determinar» que no suponga un «incremento de las cotizaciones empresariales».

La disposición adicional primera de la ley 12/2011 viene regulando el Contrato de Trabajo para el Fomento de la Contratación Indefinida (CFCI), materia modificada por la reforma de 2010. Este contrato no ha dejado de expandirse en el sentido de que son ya muy pocos los trabajadores que escapan a la posibilidad de ser contratados bajo esta modalidad contractual y sus «ventajas» son dos: a) reducción de 45 a 33 días el importe de la indemnización en el caso de extinción del contrato por causas objetivas declarado o reconocido como improcedente; b) aplicación de importantes bonificaciones y reducciones en las cuotas de la Seguridad Social. Este contrato sufre ahora nuevos retoques en la parte de colectivos contemplados, ampliándose.

Dejando al margen consideraciones de política legislativa ${ }^{24}$-la coherencia, oportunidad y conveniencia de esta medida - la decisión 
de suspender la aplicación del artículo 15.5 del ET plantea numerosas dudas, habida cuenta que la suspensión de la aplicación del precepto legal es «pura y simple», es decir, sin matices (no hay añadidos ni supresiones) y sin transitoriedades. En una primera tanda de reflexiones puede apuntarse:

- A partir del 31 de agosto de 2011 no se convierte en fijo ningún contrato como consecuencia de lo previsto en tal artículo (prestación de actividad de 24 meses dentro de un período de 30, con varias contrataciones).

- La regla afecta tanto a los contratos pretéritos, cuanto a los que discurrían al entrar en vigor y a los posteriores.

- En modo alguno puede entenderse como una especie de sanación de eventuales vicios vinculados al encadenamiento fraudulento.

- Sigue siendo posible considerar fraudulento cualquier contrato temporal (al margen de su duración), del mismo modo que sigue vigente la peculiar presunción de fijeza del artículo 15.3 del ET.

- No se ha venido a legalizar la contratación temporal sin causa, sino como medida de fomento del empleo y por un plazo de dos años.

- La regla sobre duración máxima del contrato para obra o servicio aparece ahora todavía más privada de coherencia, pero vigente.

- Nada impide reclamar la consideración como fijo de quien ya había cumplido las exigencias del artículo 15.5 del ET antes de esta modificación.

- La suspensión de efectos alcanza tanto al precepto legal cuanto a sus eventuales reiteraciones o complementos convencionales.

\section{REAL DECRETO LEY 3/2012, DE MEDIDAS URGENTES PARA LA REFORMA DEL MERCADO LABORAL}

El 12 de febrero de 2012 entró en vigor Real Decreto Ley 3/2012, de 10 de febrero, de Medidas Urgentes para la Reforma del Mercado Laboral; más allá de las hipérboles con que sus partidarios o detractores resaltan virtudes o defectos, constituye norma muy relevante, valiente, compleja y polémica. Aquí se realiza una primera y urgente aproximación a estas 64 páginas del BOE (35.525 palabras 189.440 caracteres).

y condiciones encadenen contratos temporales [...] fue establecida en 2006 durante un momento de expansión económica para favorecer la estabilidad en el empleo» y que «en la actual coyuntura, la regla, lejos de fomentar la contratación indefinida, puede estar produciendo efectos indeseados de no renovación de contratos temporales y afectando negativamente al mantenimiento del empleo, lo que aconseja su suspensión temporal». El miedo a que las empresas dejen de prorrogar o de poner en juego contrataciones de duración determinada para evitar su transformación en fijos, como consecuencia de lo previsto en el artículo 15.5 ha propiciado la más enigmática e inesperada innovación: «se suspende, durante el período de los dos años siguientes a la entrada en vigor de este $\mathrm{RD}-\mathrm{L}$, la aplicación de lo dispuesto» en tal precepto. 


\section{VII.1. Contenido de la Reforma}

No se trata ahora de desmenuzar el contenido íntegro de la norma, sino de resaltar los aspectos que parecen más relevantes.

\section{a. Apoyo a PYMES.}

El Real Decreto Ley 3/2012 considera que estas empresas soportan con mayor dificultad las cargas laborales y atiende a su dimensión para aligerar algunas de ellas.

$-<500$ trabajadores: exentas de aportación económica al Tesoro Público por despidos colectivos que afecten a mayores de 50 años.

$-<250$ trabajadores: importantes reducciones de cuotas en los contratos para la formación y el aprendizaje.

$-<50$ trabajadores: contrato de trabajo por tiempo indefinido de apoyo a los emprendedores, con posibilidad de incentivos fiscales y bonificaciones en las cuotas, siendo aplicables estas también a la transformación de contratos en indefinidos.

$-<25$ trabajadores: racionalización de la responsabilidad del FOGASA, que se limita al resarcimiento de parte de las indemnizaciones por extinciones de contratos indefinidos que no hayan sido declaradas improcedentes.

\section{b. Modernización}

- Se dan pautas lógicas y acordes con los nuevos tiempos para el trabajo a distancia (viejo trabajo a domicilio), aceptando la compatibilidad del trabajo presencial con el on line, sin menoscabo de derechos.

- Se incentiva la formación del trabajador, mediante la «cuenta» personal (en la que se recogerá la formación recibida por el trabajador a lo largo de su vida activa), los períodos de adaptación, o el reconocimiento de un permiso retribuido de 20 horas anuales (para trabajadores con más de un año de antigüedad; la formación debe estar vinculada al puesto de trabajo). La norma quiere evitar que un cambio tecnológico o de otro tipo suponga el despido del trabajador, así como fortalecer la preparación profesional de los trabajadores.

- Se refuerza el derecho a la formación: se exige que el empresario, cuando lleve a cabo una modificación técnica a la que se deba adaptar el trabajador, le ofrezca un curso para que pueda formarse. Dicho período formativo suspende el contrato y el trabajador cobra su salario. Únicamente se podrá despedir al trabajador por

LEGISLACIÓN

DE EMERGENCIA

Y REFORMA

LABORAL EN

ESPAÑA

(2011-2012)

EMERGENCY

LEGISLATION

AND LABOR

REFORM IN

SPAIN

(2011-2012) 
falta de adaptación si antes se ha facilitado esta formación sin resultados.

- Se permitirá además que los centros y entidades de formación acreditados puedan ejecutar directamente los planes de formación a nivel estatal y autonómico.

\section{c. Fomento del empleo estable y de la formación}

- Desaparece el contrato indefinido de fomento y, en su lugar, se crea otro también indefinido de apoyo a los emprendedores, para empresas de menos de 50 trabajadores, con período de prueba de un año (que en el trámite parlamentario debería reducirse sensiblemente), importantes incentivos fiscales y bonificaciones de cuotas (si se mantiene la contratación al menos 3 años) y, si el trabajador venía percibiendo una prestación contributiva de desempleo, posibilidad de compatibilizar cada mes, junto con el salario, el 25 por ciento de la cuantía de la prestación que tuviera reconocida y pendiente de percibir en el momento de su contratación.

- Se pretende dar prioridad a la colocación. A tal fin, se permite a las ETT, y a las que están en curso administrativo de serlo, actuar como agencias privadas de colocación con una mera declaración responsable de cumplir con una serie de requisitos.

- El fin de la suspensión de la aplicación de las reglas que penalizan el encadenamiento de contratos temporales (artículo 15.5 ET) se adelanta a enero de 2013.

- En materia de formación, desaparece el monopolio de las organizaciones empresariales y sindicatos más representativos y se da entrada a otros centros y entidades de formación debidamente acreditados.

- Mediante una pirueta jurídica, los planes de formación vuelven a ser estatales, pero su gestión se encomienda a las Comunidades Autónomas.

\section{d. Negociación colectiva}

- Posibilidad de revisión del convenio durante su vigencia: no a través de la Comisión Paritaria, sino de la negociadora.

- Posibilidad de descuelgue en materia salarial y en otras: tiempo de trabajo (jornada, horario, distribución, turnos), remuneraciones (sistema, cuantía), sistema de trabajo y rendimiento, funciones y mejoras voluntarias. Se mantienen las causas económicas y la exigencia de que sea pactado o arbitrado. Se abandona el camino de las modificaciones sustanciales y se acude al del descuelgue. 
- En caso de que no exista acuerdo sobre el descuelgue, las partes irán a la solución extrajudicial de conflictos y, en su caso, al arbitraje si lo han pactado en el convenio colectivo. De no ser así, una de las partes elevará el desacuerdo a la Comisión Consultiva de Convenios Colectivos nacional o sus equivalentes autonómicos, que nombrará un árbitro que resolverá en un máximo de 25 días.

- Se otorga primacía al convenio de empresa, que es inatacable por los superiores en un conjunto amplio de materias.

- Ultraactividad: máximo dos años. Pero al finalizar, lo que sucede es que se aplica el convenio de ámbito superior (si existe).

- Plazo de un año para acomodarse al nuevo sistema de clasificación profesional basado en grupos.

- Contenido mínimo: no se hace referencia al plazo máximo para el inicio de las negociaciones, la duración máxima de estas, la necesidad de adhesión a acuerdos para solución extrajudicial, las funciones específicas de la Comisión Paritaria, adopción de medidas de flexibilidad interna, etcétera.

\section{e. Flexibilidad interna}

- Hay innovaciones en cuanto a la clasificación profesional (se impone a los convenios la clasificación a base de grupos, descartando las categorías), la movilidad funcional (eliminación de restricciones) y distribución irregular de la jornada (5\% en manos del empresario, si es que los convenios o acuerdos no abordan el tema).

- Tanto para la movilidad geográfica como para la modificación sustancial de las condiciones de trabajo, las causas son más genéricas y se desvinculan de la finalidad exigida tradicionalmente. Se habla de las que estén «relacionadas con la competitividad, productividad u organización técnica o del trabajo en la empresa».

- Se reconocen posibles prioridades de permanencia adicionales a la de los representantes: trabajadores con cargas familiares, mayores de determinada edad o personas con discapacidad.

- En modificaciones sustanciales, se reduce el plazo de preaviso de 30 a 15 días, se contempla expresamente la modificación de la «cuantía salarial», junto a la estructura del salario; se reduce de 30 a 7 días el plazo de efectividad en caso de que la colectiva se adopte sin acuerdo.

- Suspensión del contrato y reducción de jornada por causas económicas: desaparece la autorización administrativa, salvo

LEGISLACIÓN

DE EMERGENCIA

Y REFORMA

LABORAL EN

ESPAÑA

(2011-2012)

EMERGENCY

LEGISLATION

AND LABOR

REFORM IN

SPAIN

(2011-2012) 
fuerza mayor; en caso de acuerdo, se mantiene la presunción de que concurren las causas y, consiguientemente, se limitan las posibilidades de impugnación; se establecen medidas de apoyo a través de bonificaciones y coordinación con el desempleo; no se aplica al sector público.

- La pasividad o el «bloqueo» de los convenios no pueden impedir que la empresa tome decisiones relevantes en materia de clasificación profesional (ahora por grupos, no por categorías), vincule salarios a productividad/resultados, disponga, si lo precisa, de un porcentaje mínimo de jornada irregular (5\%), se descuelgue no solo del salario sino también del tiempo trabajo, del sistema de trabajo, de las funciones, de las mejoras voluntarias, etcétera.

\section{f. Despido improcedente}

- Cambios muy relevantes. En despido improcedente con indemnización, el desempleo se percibe «con efectos desde la fecha de cese efectivo».

- Aunque los salarios de tramitación se suprimen con carácter general, se deroga el artículo 105.3 de la Ley Reguladora de la Jurisdicción de lo Social para permitir a la empresa defender la procedencia del despido que fue impugnado pese a haberse reconocido la improcedencia del mismo.

- Se mantienen salarios trámite en los supuestos de nulidad, donde la readmisión es forzosa, en los casos en que la empresa opte por la readmisión (y readmita efectivamente) o cuando se trata de un representante de los trabajadores (opte por readmisión o no).

- A partir de la reforma, se generaliza la indemnización por la extinción del contrato indefinido que será de 33 días por año trabajado en caso de despido improcedente, con un máximo de 24 mensualidades.

- De este modo, se abonarán 33 días por año con un máximo de 24 meses para contratos nuevos. Para contratos anteriores a 12 de febrero de 2012, se impone un doble módulo (45 días con un máximo de 42 meses teóricos para los servicios prestados hasta 12 de febrero de 2012; 33 días con un máximo de 24 meses para servicios prestados a partir del 12 de febrero de 2012), con un máximo de 720 días, salvo que el módulo privilegiado sea superior (hasta 42 meses).

\section{g. Despidos económicos («flexibilidad externa»)}

- Despidos colectivos: desaparece la autorización administrativa y el procedimiento se centra en la negociación y en el plan de recolocación para empresas que despidan a más de 100 
trabajadores (gestionado por empresa externa y especializada, al menos semestral).

- Desaparece la referencia a la razonabilidad de la medida y a la acreditación de los resultados alegados.

LEGISLACIÓN

- Se pretende dar seguridad jurídica vinculando la disminución persistente de los ingresos o ventas (como situación económica negativa) a su descenso continuado durante tres trimestres consecutivos.

- El procedimiento se simplifica notablemente: la autoridad laboral actúa de manera coordinada con la Inspección de Trabajo y con el Servicio Público de Empleo, pero no interviene en la decisión final.

- El Fondo de Garantía Salarial resarce a la empresa del abono de ocho días de la indemnización, pero solo en extinciones procedentes de contratos indefinidos en empresas de menos de 25 trabajadores.

- El control de los despidos se encomienda a las Salas de lo Social de los Tribunales Superiores de Justicia o de la Audiencia Nacional, sin vías previas.

- Se reconoce la viabilidad jurídica de estos despidos en el sector público en casos de insuficiencia presupuestaria sobrevenida y persistente. Esta medida pretende facilitar el redimensionamiento de aquellas estructuras administrativas que crecieron desmesuradamente durante la fase de fuerte crecimiento económico y que no son sostenibles desde un punto de vista financiero en el momento actual, ni existe una previsión de que lo sean en los próximos años.

- Despidos por causas objetivas no económicas. La falta de adaptación exige a la empresa dar formación. En el despido por absentismo desaparece la referencia al 2,5\% de ausencias colectivas en el centro de trabajo.

\section{h. Colaboración en la búsqueda urgente de empleo}

- Para sumar los esfuerzos urgentes de todos aquellos que pueden colaborar en la búsqueda de un puesto de trabajo, se autoriza a las Empresas de Trabajo Temporal, que cuentan con una amplia red de sucursales distribuidas por todo el territorio y con amplia experiencia en el mercado de trabajo, para actuar como agencias privadas de colocación. En ningún caso, las ETT cobrarán a los trabajadores. 
i. Modalidades contractuales: contrato para la formación y el aprendizaje

- Se eleva la edad máxima para tener acceso a este tipo de contrato, teniendo en cuenta la prolongación de los períodos de estudio y la elevada tasa de desempleo en el colectivo de menores de 30 años hasta que la tasa de desempleo baje del 15\%.

- Tras agotar un período de formación en una actividad, el trabajador podrá utilizar esta modalidad de contrato en otros sectores, lo que mejorará su empleabilidad y le permitirá una segunda oportunidad. Además, podrá recibir la formación en la propia empresa, si dispone de instalaciones y personal adecuado.

\section{j. Lucha contra absentismo y fraude}

- Se impulsará que los desempleados que estén cobrando la prestación realicen servicios de interés general en beneficio de la comunidad a través de convenios de colaboración con las Administraciones públicas.

- Para combatir comportamientos individuales de absentismo injustificado que ocasionan a la empresa un elevado coste económico y organizativo, se elimina la vinculación del grado de absentismo del trabajador y la plantilla para justificar el absentismo como causa de despido. A partir de ahora solo se tendrá en cuenta el absentismo del trabajador.

- Se mejorará la eficacia de la evaluación de la incapacidad temporal a través de las Mutuas de accidentes de trabajo.

\section{VII.2. Opinión técnica}

La norma en cuestión es «de urgencia» pero en modo alguno improvisada, presupone toda una concepción en aspectos clave de las relaciones laborales y deja a un lado habituales prejuicios o miedos; no se piensa en el qué dirán ni se busca favorecer a una sola de las partes. Es como si nuestro sistema laboral hubiera sido sometido a una auditoría y ahora se ejecutasen las recomendaciones del pertinente Informe sobre anomalías, incoherencias, proteccionismos excesivos e injustificados, discordancias, rigideces, etcétera.

Las novedades no propician la indiferencia. Basta ver las primeras reacciones desde medios patronales («se trata de una reforma amplia, que incide sobre aspectos fundamentales y en la buena dirección, a la espera de los detalles técnicos» ${ }^{25}$ ) y contrastarlas con las sindicales 
(«una norma clasista que impone la confiscación violenta de espacios decisivos de poder contractual colectivo y de derechos laborales básicos ligados a las garantías de empleo» $\left.{ }^{26}\right)$. Con el ánimo de contribuir a la generación de la propia opinión se exponen seguidamente algunas reflexiones y puntos de vista.

- El real decreto ley aborda temas mayoritariamente coincidentes con los retocados durante los dos años anteriores, por lo que estamos ante una ENMIENDA virtual a esa etapa.

- En varias cuestiones (contratos indefinidos de fomento, despido exprés, ultraactividad, ETT, tiempo parcial, formativos, etcétera) actúa con CLARIDAD, desechando perífrasis.

- Se amplía y normaliza el contrato a tiempo parcial, que admite la realización de horas extras (además de las complementarias) en proporción a la jornada.

- Remodela distintos bloques (colectivo, individual, procesal, Seguridad Social, Empleo, Jurisdicción) y es TRANSVERSAL.

- Mantiene la moda de convertirse en proyecto, generando regulación BIFÁSICA y claudicante.

- FUNCIONALMENTE es variado: modifica, concuerda, añade, retoca, innova, deroga, precisa, resucita, clarifica, remite, etcétera.

- Aborda ciertos TABÚES (45 días/42 meses, salarios de tramitación, autorización administrativa, derechos adquiridos).

- Reduce la protección clásica frente al DESPIDO individual (indemnización, absentismo suficiente, consecuencias de reconocer la improcedencia, etcétera). Más que la rebaja a 33 días (con transitoriedad enrevesada), destaca la casi supresión de los salarios de trámite si se abona indemnización (no basta la opción).

- ElIMINA intervencionismo administrativo en novaciones (traslados, suspensiones, reducciones de jornada, despidos), conservándolo para la fuerza mayor. Pero el papel de la Administración no se suprime sino que se transforma.

- La jurisdicción social apenas se ha estrenado como fiscalizadora de autorizaciones en los ERE (desaparece el objeto controlado); pero su nueva función es tanto o más decisiva.

LEGISLACIÓN

DE EMERGENCIA

Y REFORMA

LABORAL EN

ESPAÑA

(2011-2012)

EMERGENCY

LEGISLATION

AND LABOR

REFORM IN

SPAIN

(2011-2012) 
- La norma redefine las causas económicas, con el claro propósito de restringir la discrecionalidad judicial, pero sería un error pensar que esta nueva identificación sobre su concurrencia (o la persistencia de las pérdidas) elimina el debate. Acierta con la relevancia del plan de recolocación.

- SimPLificA la farragosa ordenación de algunos temas (contenido de convenios, modificaciones sustanciales, procedimiento de negociación, causas despidos económicos o análogos).

- INNOVA en formación ocupacional («cuenta» personal, períodos de adaptación, 20 horas anuales retribuidas, fin a la exclusividad de la gestión por agentes sociales) y teletrabajo.

- Deroga el contrato indefinido de fomento pero lo sustituye por otro de apoyo a los emprendedores, con un período de prueba anual quizá INCONSTITUCIONAL, que desnaturaliza su razón de ser.

- MODERNIZA aspectos que debían haber sido asumidos por la negociación colectiva (clasificación profesional por grupos, retribuciones vinculadas a resultados, jornada irregular, movilidad, descuelgues, ultraactividad bienal).

- El DESCUELGUE se admite para más materias, pero sigue siendo causal y pactado (o arbitrado). La PRIMACÍA del convenio de empresa es inatacable por los superiores (cautela coherente).

- Neutraliza ciertos criterios judiciales poco acordes con la flexiseguridad (causas modificativas o extintivas).

- ACABA con viejas incoherencias legislativas (modificación sustancial legal y contraria a la formación profesional, concurrencia de convenios prohibida y luego admitida).

- DinAMIZA la intermediación en el empleo (ETT) y retoca (pero no elimina) las bonificaciones.

- RETOMA el arbitraje obligatorio como solución última a ciertos conflictos de regulación. No consigue eliminar los recelos ante el mismo.

- PARTICUlARIZA cuestiones de actualidad (expresa admisión de ERE en el ámbito público y en grandes empresas con beneficios, limitaciones retributivas o indemnizatorias en el sector financiero, caducidad de las vacaciones).

- ACENTÚA la dualidad entre trabajadores blindados (nulidad del despido si no hay procedencia) y ordinarios; es previsible un aumento de los primeros. 
- No aparece el contrato único, ni el idealizado Fondo austríaco (reconduce acertadamente el papel del FOGASA), ni deroga el «contrato para la formación y aprendizaje» (remodelado).

- Concibe las medidas de flexibilidad interna como coadyuvantes de la estabilidad, reactiva el artículo 15.5 del ET (sin afrontar las enormes dudas aplicativas de los torpes avatares normativos) y conserva medidas de apoyo (incluso reposiciones) a la suspensión cuando la empresa atraviesa dificultades.

- Desde la óptica de los derechos, elimina garantías históricas de los trabajadores (los 45 días de salario por año trabajado en las indemnizaciones por despido improcedente, el control administrativo en los ERE o en los traslados colectivos, los salarios de tramitación).

- Poniendo término a la larga espera (desde 1994 lo pedía el ET) se arrumba el muy consolidado concepto de categoría profesional, abriendo un paréntesis de adaptación.

- Permite a las empresas y a los representantes de los trabajadores negociar con libertad, sin el corsé de lo pactado «en la cumbre», con los peligros y ventajas que ello comporta.

- Aumenta las posibilidades de flexibilidad interna (descuelgues en más materias, movilidad funcional en el grupo, modificaciones sustanciales que permiten reducir el salario).

- Permite a las ETT (y aun las que están en trámite de serlo) actuar como agencias de colocación, privatizando aun más la intermediación en el mercado de trabajo.

- Realmente abarata el despido, pero no tanto por la rebaja indemnizatoria del improcedente cuanto por la eliminación de los salarios de tramitación, en línea con lo hecho en 2002 durante unos meses.

- Fomenta el empleo y la contratación con bonificaciones e incentivos fiscales.

Los cambios están llenos de posibilidades interpretativas; la redacción de los preceptos es generalmente mejor que la precedente. La ordenación por bloques temáticos parece artificiosa; la extraordinaria y urgente necesidad que todo real decreto ley exige no concurre respecto de algunas materias. Constituye un lógico reduccionismo de primera hora considerar a la norma meramente abaratadora y facilitadora del despido, del mismo modo que una ilusión pensar que per se generará masiva creación de empleo. 
Es innegable que, como hiciera el Real Decreto Ley 7/2011, moderniza y aborda cuestiones de actualidad, al tiempo que relevantes para el sistema de relaciones laborales. Al igual que entonces, la contestación sindical, la crítica de los estudiosos, el desdén de los observadores, la impugnación de otras fuerzas políticas o las reclamaciones empresariales son reacciones tan lógicas cuanto inocuas a la hora de examinar y aplicar una norma con rango de ley que, por ello mismo, solo en la medida que sea declarada contraria a la Ley Fundamental por nuestro TC podría inaplicarse.

En vista a las materias que se modifican y la intensidad de los cambios, algunas voces están hablando de «un nuevo modelo de relaciones laborales», lo que sin duda es exagerado. Otra cosa es que estemos ante modificaciones de alcance emparentado con las del año 1994.

Quiere el Real Decreto Ley 3/2012 que se abandone la consideración del trabajador como contratante débil; que los sindicatos, aunque reforzados en la empresa, pierdan también - los más representativosimportantes prerrogativas: exclusividad en la formación, negociación sectorial; en fin, la Administración asume la mayoría de edad de la regulación de empleo y abandona controles propios de otra época (despidos colectivos, traslados).

Al eliminar cautelas, autorizaciones, prohibiciones, garantías, automatismos o generalizaciones, aumenta la importancia del asesoramiento técnico para todos los implicados. El papel de los directores de Recursos Humanos, graduados sociales, abogados $\mathrm{u}$ otros profesionales emparentados pasa a ser cada vez más decisivo porque la realidad depende cada vez menos de lo que digan las normas heterónomas y más de las prácticas, acuerdos o convenios. 